\title{
A ABORDAGEM BILÍNGUE PARA CRIANÇAS COM SURDEZ E A PRÁTICA DOCENTE: EM PERSPECTIVA OS OBJETOS DE APRENDIZAGEM
}

\author{
ANA SILVIA MOÇO APARÍCIO* \\ AMANDA CAVALCANTE OLIVEIRA** \\ ELIZABETE CRISTINA COSTA RENDERS***
}

\begin{abstract}
RESUMO
Apresenta os resultados parciais de uma pesquisa que objetiva, de forma geral, investigar as práticas adotadas na abordagem bilíngue para crianças com surdez, em salas de aula regular. De modo específico, busca compreender como se dá o uso e circulação da Libras (Língua Brasileira de Sinais) e do Português em duas salas de uma escola de educação infantil. Metodologicamente, trata-se de uma pesquisa empírica de carácter qualitativo, cujo objeto de estudos é a prática docente em uma escola vinculada à rede pública de ensino de uma cidade da região do grande $\mathrm{ABCD}$ paulista, Brasil. Os procedimentos metodológicos se deram em três etapas: entrevista semiestruturada com quatro professoras, observação em sala de aula e desenvolvimento de objeto de aprendizagem. Esta investigação toma como aportes teóricos: a linguagem como prática social (BAKHTIN, 1986), a surdez como experiência visual (SKLIAR, 1999) e a abordagem bilíngue para surdos (FAVORITO; SILVA, 2008). Os resultados preliminares
\end{abstract}

\footnotetext{
* UNICAMP

** Mestre em Educação pelo Programa de Pós-graduação em Educação da Universidade Municipal de São Caetano do Sul a dissertação: Abordagem bilíngue para crianças com surdez: propostas de práticas educativas na educação infantil, sob orientação da professora Dra. Elizabete Cristina Costa Renders.

*** Professora titular do Programa de Pós-graduação em Educação da Universidade Municipal de São Caetano do Sul. Orientadora do trabalho.
} 
apontaram para a constituição de dois momentos distintos na escola. Primeiro: o atendimento educacional especializado (AEE) em Libras, no período regular, por meio da parceria entre o professor regente e o professor mediador. Segundo: o atendimento educacional especializado em Português, realizado com o uso da língua de instrução da criança com surdez (a Libras), trabalhando a língua adicional (o Português) na modalidade escrita. Constatou-se a necessidade de mediações sígnicas acessíveis (REILY, 2004) no trabalho interacional e do desenvolvimento de objetos de aprendizagem que atendam aos critérios de acessibilidade, interatividade, cooperação, cognição, afetividade, disponibilidade e reusabilidade (BRAGA, 2014).

Palavras-chave: Abordagem bilíngue para surdos; Prática docente; Objetos de aprendizagem; Português como língua adicional.

\begin{abstract}
It presents the partial results of a research that aims, in general, to investigate the practices adopted in the bilingual approach for deaf children in regular classrooms. Specifically, it seeks to understand how the use and circulation of Libras (Brazilian Sign Language) and Portuguese are given in two rooms of a kindergarten. Methodologically, this is an empirical research of a qualitative nature, whose object of study is the teaching practice in a school linked to the public school system of a city of the great ABCD region of São Paulo, Brazil. The methodological procedures were developed in three stages: a semi-structured interview with four teachers, observation in the classroom, and the development of learning object. This research takes as theoretical contributions: language as a social practice (BAKHTIN, 1986), deafness as a visual experience (SKLIAR, 1999) and the bilingual approach for the deaf (FAVORITO; SILVA, 2008). The preliminary results pointed to the constitution of two distinct moments in the school. First, the specialized educational service (AEE) in Libras, in the regular period, through the partnership between the
\end{abstract}


teacher regent and the mediator teacher. According to the specialized educational service (AEE) in Portuguese, made using the language of instruction of the deaf child (the Libras), working the additional language (Portuguese) in the written mode. It was observed the need for accessible signal mediations (REILY, 2004) in interactional work and the development of learning objects that meet the criteria of accessibility, interactivity, cooperation, cognition, affectivity, availability and reusability (BRAGA, 2014).

Key words: a bilingual approach for the deaf; teaching practice; learning objects; Portuguese as an additional language.

\section{INTRODUÇÃO}

Este texto discorre sobre os resultados parciais de uma pesquisa que objetiva, de forma geral, investigar as práticas adotadas na abordagem bilíngue para crianças com surdez, em salas de aula regular, nas escolas brasileiras. De modo específico, busca compreender como se dá o uso e a circulação da Libras (Língua Brasileira de Sinais) e do Português em duas salas de uma escola de educação infantil.

Metodologicamente segue os procedimentos de uma pesquisa empírica de carácter qualitativo, cujo objeto de estudos é a prática docente em uma escola vinculada à rede pública de ensino de uma cidade situada na região do grande ABCD paulista, Brasil. A referida escola atende garotas e garotos de três a seis anos de idade, sendo um polo para educação de garotas e garotos com surdez segundo a perspectiva inclusiva; em outras palavras, esses escola é frequentada por crianças surdas e ouvintes em período integral.

Esta pesquisa é desenvolvida no contexto da política educacional brasileira (BRASIL, 2005), que dispõe sobre a garantia dos direitos linguísticos de crianças com surdez (QUADROS, 2009), oportunizando o atendimento educacional especializado (AEE) que privilegia a Língua Brasileira de Sinais (Libras), como língua materna, e o Português, como língua adicional no Brasil. 
Os procedimentos metodológicos estão organizados em três etapas: entrevista semiestruturada com quatro professoras; observação em sala de aula e desenvolvimento de objeto de aprendizagem num processo de avaliação; validação nas salas de aula da referida escola. Já estamos iniciando a terceira etapa. Uma vez localizado, no estado da arte, o problema da monocultura linguística na educação de surdos, seguiu-se perguntando pela efetiva abordagem bilíngue para surdos nas práticas docentes desenvolvidas em sala de aula das escolas brasileiras.

Constatamos a necessidade da constituição de mediações sígnicas acessíveis (REILY, 2004) no trabalho interacional inseparável da participação pelo uso da linguagem, bem como do desenvolvimento de novos objetos de aprendizagem que atendam a critérios, tais como: acessibilidade, interatividade, cooperação, cognição, afetividade, disponibilidade, portabilidade, usabilidade e reusabilidade (BRAGA, 2014).

Nossa investigação tem os seguintes aportes teóricos: a linguagem como prática social (BAKHTIN, 1986), a surdez como uma experiência visual (SKLIAR, 1999) e a abordagem bilíngue para surdos (FAVORITO; SILVA, 2008). Os resultados preliminares têm apontado para a constituição de dois momentos distintos na escola. Primeiro, o atendimento educacional especializado (AEE) em Libras, no período regular, por meio da parceria entre o professor regente e o professor mediador. Segundo, o AEE em português, realizado com o uso da língua de instrução da criança com surdez (a Libras), trabalhando a língua adicional (o Português) na modalidade escrita.

Temos em perspectiva, portanto, a produção de um objeto de aprendizagem fundamentado no design universal para aprendizagem que contribua para a circulação da Libras como primeira língua e do Português como língua adicional (SCHLATTER; GARCEZ, 2009) nas escolas de educação infantil.

O texto ora apresentado está organizado em duas seções. A primeira localiza o problema da pesquisa no contexto da 
realidade brasileira, considerando os direitos linguísticos das crianças com surdez nas escolas brasileiras. A segunda seção discorre sobre a abordagem bilingue para garotas e garotos com surdez, apontando os desafios do uso da Libras e do Português na educação de surdos nas escolas brasileiras.

\section{OS DIREITOS LINGUÍSTICOS DAS CRIANÇAS COM SURDEZ NAS ESCOLAS BRASILEIRAS}

A proposta atual para a educação dos surdos no Brasil fundamenta-se na abordagem bilíngue, reconhecendo que as pessoas com surdez têm direito ao acesso e uso da Libras e do Português na instituição educacional, bem como as pessoas ouvintes têm a oportunidade de aprender uma nova língua (na modalidade sinalizada), ampliando sua percepção linguística. Todavia, importa retomarmos o percurso desta conquista para entender os desafios da prática docente no campo da abordagem bilíngue para crianças com surdez no Brasil.

\subsection{Percurso da política de educação ESPECIAL NO BRASIL}

No Brasil, os primeiros marcos da educação especial ocorreram no período imperial, com a criação dos primeiros institutos especializados para atender pessoas com deficiência. Esses tinham como base os ideais franceses.

Em 1854 foi fundado o Imperial Instituto dos Meninos Cegos, que 30 anos mais tarde passou a se chamar Instituto Benjamin Constant. Já em 1857 criou-se o Instituto Imperial dos Surdos Mudos, que 100 anos depois foi denominado Instituto Nacional de Educação de Surdos. Ainda no período imperial, em 1874, as pessoas com deficiência mental tiveram acesso a assistência em hospitais psiquiátricos e apenas em 1930 surgiram as primeiras instituições auxiliares para esses sujeitos. Todavia, o auxílio era voltado para a filantropia e para o assistencialismo 
em instituições segregacionistas, que visavam o atendimento clínico terapêutico.

Em 1961 foi promulgada a primeira lei federal que indicava a necessidade de serviços de educação especial, a Lei de Diretrizes e Bases da Educação Nacional N. ${ }^{\circ}$ 4024/61, que previa o direito dos excepcionais à educação, preferencialmente, no sistema de ensino regular (BRASIL, 1961). Anos depois, em 1973, o Ministério da Educação e Cultura criou o Centro Nacional de Educação Especial, que passou a ser responsável pela organização e criação das primeiras políticas especiais para atendimento das pessoas com deficiência.

Somente em 1988, com a promulgação da Constituição Federal, institui-se o Estado de Direito e o entendimento da educação como direito também a todas as pessoas com deficiência. Todavia, a inclusão aponta para a matrícula, preferencialmente na rede regular de ensino, com a possibilidade do atendimento educacional especializado nas escolas especiais.

Em âmbito internacional, na década de 1990, iniciaram-se as mudanças visando um novo modelo de educação para as pessoas com deficiência. Em 1994, com a promulgação da Declaração de Salamanca, o acesso à educação passou a ser direito de todos, sem exceção, e, portanto, também à criança com deficiência ou não. Dois anos mais tarde, os princípios descritos na Declaração de Salamanca foram incorporados ao marco regulatório brasileiro e iniciaram-se as matrículas desse público nas salas comuns de ensino.

Já em 1999 a regulamentação do Decreto N. 3.298 (BRASIL, 2004, p.29) determina em seu art. 24, inciso II “a inclusão, no sistema educacional, da Educação Especial como modalidade de educação escolar que permeia transversalmente todos os níveis e as modalidades de ensino", desde a educação infantil até o ensino superior. Com isso, as diretrizes asseguravam o Atendimento Educacional Especializado, de modo complementar ou suplementar à escolarização do aluno. Destacam-se a premissa do respeito à 
diversidade e da busca pelos conhecimentos sobre as especificidades dos alunos com necessidades educacionais especiais.

Em mais uma etapa de inclusão desse público específico, em 2006 a Convenção sobre os Direitos das Pessoas com Deficiência (ONU), assinada em Nova Iorque, estabelece um sistema de educação inclusiva que atenda a todos os níveis de ensino, em ambientes que promovam o desenvolvimento acadêmico e social.

Um ano depois foi reafirmada a visão sistêmica da educação que busca superar a oposição entre o ensino regular e a educação especial, por meio do Plano de Desenvolvimento da Educação: razões, princípios e programas.

Desde 2014, o Plano Nacional de Educação - PNE (BRASIL, 2014) - está em vigor com diretrizes e bases para as políticas educacionais. São 20 as metas que norteiam a educação brasileira, dentre as quais há um ponto específico sobre a educação especial inclusiva, a saber: a Meta 4 que orienta o trabalho junto ao público alvo da educação especial.

\subsection{Percurso da política de educação DE SURDOS NO BRASIL}

É de conhecimento amplo que no decorrer da história da humanidade as pessoas com surdez sempre enfrentaram obstáculos para participar da educação escolar e de suas propostas educacionais. $\mathrm{Na}$ Antiguidade, os surdos eram considerados seres incapazes de aprender e, portanto, sujeitos sem direitos legais por não conseguirem estabelecer (segundo se entendido naquela época) uma comunicação efetiva. Todavia, é possível localizar diferentes tentativas de promover a comunicação entre os surdos. No século XVI, Ponce de León, monge beneditino espanhol, iniciou as primeiras tentativas de ensinar o surdo, de modo individualizado e não formal, e assim tentar torná-lo um sujeito possuidor de direitos.

Na França, em 1750, o abade Charles Michel de L’Epée iniciou a instrução de crianças surdas e 10 anos depois forma- 
lizou a pioneira escola para este público, que se tornou grande referência para criação de outras escolas. No século seguinte, em 1817, baseado na metodologia de L’Epée, Thomas Hopkims Gallaudet fundou a primeira escola americana para surdos, utilizando a língua de sinais.

No Brasil, a educação de surdos foi decorrente das lutas e conquistas históricas europeias e em 1857 foi fundado o Instituto Imperial de Surdos Mudos, no Rio de Janeiro, hoje conhecido como Instituto Nacional de Educação de Surdos. Por intermédio deste instituto a língua de sinais passou ter maior visibilidade social em nosso país. Porém, com as mudanças na direção da instituição houve também alterações no método de ensino dos surdos. Assim, instituto passou a defender o método oralista, que trabalhava com o treino da fala e da leitura labial, proibindo a comunicação por sinais.

Décadas depois, em 1880, durante o Congresso Internacional de Surdo Mudez, ocorrido em Milão, o método oral foi eleito como o mais adequado e passou a ser adotado nas escolas de surdos. Devido a isso, a língua de sinais passou a ser abolida das escolas. Mas esta continuou em uso, de forma clandestina, nas comunidades surdas.

No Brasil, em 1987, foi fundada a Federação Nacional e Integração de Surdos - FENEIS, na cidade do Rio de Janeiro, que se tornou referência nacional nas questões que envolviam o sujeito surdo. Em 1993 tiveram início as discussões sobre um projeto de lei que regulamentasse a língua de sinais como língua oficial do país. Todavia, apenas em 2002, com a promulgação da Lei No 10.436/02 (BRASIL, 2002) a Língua Brasileira de Sinais (Libras) foi reconhecida como meio legal de comunicação e expressão dessa comunidade neste país.

Em 2005 foi aprovado o Decreto $n^{\circ}$ 5.626/05 (BRASIL, 2005), que especificou os direitos do cidadão com deficiência auditiva e com surdez nas áreas da saúde, educação e trabalho. Em 2010, a profissão de Tradutor e Intérprete de Libras foi re- 
gulamentada pela Lei no 12.319/10 (BRASIL, 2010), que dispõe sobre a sua formação e suas atribuições funcionais. Destaca-se, no cenário brasileiro, a relevância da inserção desse profissional nos espaços públicos, em geral, e nas instituições educacionais, em especial.

Em 2014 foram aprovadas, no Plano Nacional de Educação - PNE, a oferta e a garantia da escola bilíngue para surdos. Essa abordagem de ensino permite o acesso pela criança com surdez, o mais precocemente possível, ao ensino de suas duas línguas: Libras (língua materna) e Português (como língua adicional).

\section{OS DESAFIOS DA PRÁTICA DOCENTE NA ABORDAGEM BILÍNGUE PARA CRIANÇAS COM SURDEZ}

A abordagem bilíngue para surdos tem colaborado para o reconhecimento do valor de ambas as línguas (Libras e Português) na vida da comunidade surda muda, entendendo a língua como fator de inclusão social e educacional. Por outro lado, tem provocado uma inversão epistemológica para o problema da surdez e para a educação bilíngue. Em face dessa questão, Skliar pergunta: "quais os problemas que nós, ouvintes, temos ao pensar a educação bilíngue? Quais os mecanismos que, nós, ouvintes, temos construído - e/ou inventado - para compreender o bilinguismo dos surdos?" (SILVA; VIZIM, 2001, p.107). Enfim, o reconhecimento da língua de sinais causa, aos oralizados, desconforto, porque os insere num campo linguístico que não dominam.

Nesse cenário, importa considerarmos esta novidade (a abordagem bilingue) como uma oportunidade de constituição de novas e inclusivas práticas educativas nas escolas, especialmente, na educação infantil quando um dos temas centrais é o desenvolvimento linguístico das crianças, sejam surdas ou ouvintes. 


\subsection{A Língua de SINAIS COMO NOVIDADE PARA PROFESSORES}

Apesar dos estudos científicos e linguísticos serem recentes, sabe-se que, como as línguas orais, também a de sinais é constituída por mecanismos fonológicos, semânticos, sintáticos e morfológicos, tendo como principal característica seu caráter visual-espacial.

Cada país tem sua própria língua de sinais, e, assim como qualquer outra língua, esta apresenta variações linguísticas dependendo das diferenças de cada lugar. Podemos destacar os aspectos socioculturais e o momento histórico de exposição, ou seja, o regionalismo e/ou sotaques. A língua de sinais é aprendida naturalmente pelo sujeito surdo se ele estiver inserido em um ambiente que propicie a aprendizagem. Portanto, um dos desafios será a aquisição de língua das crianças surdas filhas de casais ouvintes.

Diante dessa situação, os pesquisadores Kyle e Woll (1985) apontam algumas propriedades exclusivas das línguas de sinais que podem contribuir para a comunicação dessas pessoas, tais como o uso de gestos simultâneos, a organização e o espaço utilizados. Assim, as línguas de sinais possuem uma modalidade de produção motora (mãos, face e corpo) e uma modalidade de percepção visual.

Já Stokoe (1960), por sua vez, explica que as línguas de sinais são sistemas dinâmicos que, com a influência da língua oral majoritária do país, sofrem adaptações e mudanças. Sua estrutura morfológica é constituída por cinco parâmetros linguísticos: configuração de mão, ponto de articulação, movimento, orientação e expressão.

A configuração de mão (CM) é a forma que a mão se configura inicialmente para executar o sinal. Esta pode ser configurada por uma letra do alfabeto manual, por um número ou outra configuração.

O ponto de articulação (PA) é o local que a mão incide para execução do sinal. Este pode ser alguma parte do corpo 
ou um espaço neutro à frente ou ao lado do corpo, assim como exemplificado na imagem.

O movimento (M) é a deslocação da mão no espaço para a execução do sinal. Há sinais que não têm movimento, sendo estes considerados estáticos. A orientação ou direcionalidade (O/D) é a orientação, direção e sentido do movimento na execução do sinal.

Há também as expressões que podem ser faciais e/ou corporais $(\mathrm{EF} / \mathrm{C})$, complementos necessários para compreensão do sinal. Evidentemente as faciais são expressas pelo rosto e as corporais, pelo corpo todo - para dar vida e entendimento do que se quer comunicar.

No passado, houve a pretensão de se criar uma língua de sinais universal, conhecida como Gestuno ou Língua Gestual Internacional $^{1}$ (GESSER, 2009), porém, como toda língua, ela não foi capaz de agregar todas as questões culturais. Com isso, atualmente, o Gestuno é utilizado apenas em encontros, convenções e competições internacionais, como forma de comunicação global.

Embora haja semelhanças ou aspectos comuns entre as línguas de sinais, devido a influências linguísticas, estas são autônomas, não derivando das línguas orais e possuem peculiaridades que as distinguem umas das outras. Ou seja, a língua de sinais não é apenas uma representação pantomímica da realidade ou um sistema icônico, pois pode ser arbitrária, não tendo qualquer semelhança com a imagem que queira se referir, como também, tampouco, é a datilologia da palavra referida.

É fundamental destacar que as línguas de sinais não seguem a mesma ordem e estrutura das frases das línguas orais, isto é, uma palavra após a outra. O mais importante nas línguas de sinais é representar a informação, reconstruir o conteúdo visual da informação, pois os surdos lidam com memória visual.

1 Gestuno ou Língua Gestual Internacional é uma linguagem auxiliar internacional, muitas vezes usada pelos surdos em conferências internacionais, ou informalmente, quando viajam. 
Enfim, a língua na modalidade sinalizada é natural e tão complexa quanto as demais línguas na modalidade oralizada ou escrita. A língua sinalizada dispõe de recursos expressivos suficientes para permitir aos seus usuários se referir sobre qualquer assunto, em qualquer situação. Dessa forma, as diferentes línguas de sinais possuem desiguais representações sociais que variam de acordo com o contexto político, econômico e cultural de cada país. Algumas nações já reconheceram a modalidade sinalizada como língua oficial, regulando-a, constitucionalmente. Mas outras sequer mencionam projetos de lei neste sentido.

\subsection{O português como língua adicional na educação de crianças com surdez}

A história da educação de surdos traz as marcas do modelo clínico terapêutico (surdez como anormalidade) e da ouvintização dos sujeitos surdos (contraste binário). Atualmente, mesmo com a conquista dos direitos linguísticos na educação escolar (Libras como L1 e língua de instrução), persistem os processos de apagamento desta diferença nos sistemas educacionais. Há, portanto, que considerar a educação bilíngue para surdos numa dimensão política e epistemológica - ou seja, surdez como diferença numa dimensão política (SKLIAR, 1999).

Ao assumirmos a concepção dialógica de linguagem (BAKHTIN, 1986), considerada como lugar de interação humana em elaboração constante por sujeitos históricos e sociais, entendemos que o ensino da língua, em qualquer contexto, fundamenta-se na ideia da constitutividade do sujeito na e pela linguagem.

No que se refere ao ensino e aprendizagem da língua portuguesa para surdos, na perspectiva bilíngue, o português é considerado como língua adicional, pois parte da língua materna e há uma tendência metodológica de se valorizar o contexto do aluno desde suas práticas sociais, os valores de sua comunidade e uma visão crítica da aprendizagem da língua (SCHLATTER; GARCEZ, 2012). Com isso, a língua adicional também faz parte 
da constituição desse sujeito e não se trata de uma aquisição separada da língua que ele já conhece e domina.

A língua adicional é construída, portanto, a partir da língua ou das línguas que o aluno já conhece, com benefícios para ele próprio e para a coletividade da qual participa. Segundo o Decreto de Libras, bem como a Política Nacional de Educação Especial na Perspectiva da Educação Inclusiva (BRASIL, 2008), na educação de crianças com surdez deve-se privilegiar o ensino da língua portuguesa na modalidade escrita. Portanto, esta dinâmica traz uma nova discussão no ensino do português como língua adicional. Há que se reelaborar as estratégias de ensino no sentido do uso da modalidade escrita neste processo.

Uma das ações já desenvolvidas neste percurso investigativo foi a sinalização do espaço escolar, e para tal adotamos a abordagem bilíngue no sentido da constituição de um ambiente bilíngue com a acessibilidade necessária para as crianças com e sem surdez. Iniciamos um trabalho de reconhecimento dos espaços escolares, buscando estabelecer juntamente com o grupo aquilo que mais se destacava como representativo em tais espaços.

Realizamos, na sequência, um trabalho de registro fotográfico dos espaços, selecionando a imagem que representaria o espaço cujo elementos principais estivessem presentes. Pensando, ainda, que a escola de educação infantil é um ambiente que deve promover a aquisição de língua, propusemos ao grupo a inserção da palavra escrita em Português, para que, assim, as duas línguas circulassem no ambiente escolar de forma a auxiliar no processo de aquisição do código de escrita.

Finalizamos as placas de sinalização e as fixamos em uma altura compatível com a das crianças, garantindo o acesso visual à mensagem transmitida.

No geral, observamos que as crianças surdas e ouvintes fizeram uso da sinalização, apontando para a função social da placa de identificação, seja nos termos da localização e mobilidade num espaço ou da interação com os colegas. 


\section{CONSIDERAÇÕES FINAIS}

Os resultados preliminares desta pesquisa apontaram para a constituição de dois momentos distintos na escola. Primeiro, o atendimento educacional especializado (AEE) em Libras, no período regular, por meio da parceria entre o professor regente e o professor mediador. No segundo momento deu-se o atendimento educacional especializado (AEE) em Português, realizado com o uso da língua de instrução da criança com surdez (a Libras), trabalhando a língua adicional (o Português) na modalidade escrita.

Como já mencionado, constatou-se a necessidade de mediações sígnicas acessíveis (REILY, 2004) no trabalho interacional e do desenvolvimento de objetos de aprendizagem que atendam aos critérios de acessibilidade, interatividade, cooperação, cognição, afetividade, disponibilidade e reusabilidade (BRAGA, 2014).

Ao considerarmos esta realidade educacional na escola pública investigada, propusemos uma abordagem bilíngue por meio de um trabalho de identificação dos espaços escolares. Utilizamos placas de sinalização com o Português e a Libras. Nosso objetivo foi possibilitar apropriação das línguas e ocupação dos espaços da escola por todas as crianças (sejam surdas ou ouvintes). Neste processo nos apoiamos nos estudos de SKLIAR (1999), que entende a surdez como uma experiência visual, indicando que não é possível aceitar o visual da língua de sinais e continuar disciplinando a mente e o corpo das crianças surdas como sujeitos que vivem uma experiência auditiva. Portanto, procuramos identificar os espaços - de modo que as crianças com surdez pudessem, autonomamente, reconhecer tais locais, se deslocar entre eles com autonomia e, simultaneamente, aprimorar seus conhecimentos sobre as duas línguas: a Libras e a portuguesa. 


\section{REFERÊNCIAS}

BRASIL. Plano de Desenvolvimento da Educação: razões, princípios e programas, 2007. Disponível em: http://portal.mec.gov.br/arquivos/livro/ livro.pdf. Acesso em: Ago. 2018.

BAKHTIN, M. Marxismo e filosofia da linguagem. 3.ed. São Paulo: Hucitec, 1986.

BRAGA, J. C. Objetos de Aprendizagem: Introdução e Fundamentos. Juliana Braga (organizadora). Santo André: Editora da UFABC, 2014.

BRASIL. Ministério da Educação. A Política Nacional de Educação Especial na Perspectiva da Educação Inclusiva. Brasília: MEC, 2008. Disponível em: http://peei.mec.gov.br/arquivos/politica_nacional_educacao_especial. pdf. Acesso em: Set/2017.

BRASIL. Ministério da Educação. Decreto $N^{\circ} 5.626$ de 2005: regulamenta a Lei N. 10.436, de 24 de abril de 2002. Brasília: MEC, 2005.

BRASIL. Lei 4.024, de 20 de dezembro de 1961. Fixa as Diretrizes e Bases da Educação Nacional. Brasília: DF. 1961.

BRASIL. Constituição Federal (1988). Constituição da República Federativa do Brasil. Brasília: Senado, 1988.

BRASIL. Decreto 3.298, de 20 de dezembro de 1999. Regulamenta a Lei no 7.853, de 24 de outubro de 1989, dispõe sobre a Política Nacional para a Integração da Pessoa Portadora de Deficiência, consolida as normas de proteção e dá outras providências. Disponível em: http://www.planalto.gov.br/ccivil_03/ decreto/D3298.htm - Acesso em 13/08/2018.

BRASIL. Decreto $\mathbf{n}^{\mathbf{0}} \mathbf{5 . 6 2 6 / 2 0 0 5}$, de 24 de abril de 2005. Especifica os direitos do cidadão com deficiência auditiva e com surdez nas áreas da saúde, educação e trabalho. Disponível em: http://www.planalto.gov.br/ccivil_03/_Ato20042006/2005/Decreto/D5626.htm. Acesso em: Ago/2018.

BRASIL. Secretaria de Educação Especial. Política Nacional de Educação Especial na Perspectiva da Educação Inclusiva. Brasília, DF, jan. 2008.

BRASIL. Lei $\mathbf{n}^{\mathbf{0}} \mathbf{1 2 . 3 1 9 / 2 0 1 0}$, de 01 de setembro de 2010. Regulamenta a profissão de Tradutor e Intérprete de Libras. A consulta se deu por meio eletrônico? Em caso afirmativo, colocar: Disponível em: http://www.planalto.gov. br/ccivil_03/_ato2007-2010/2010/lei/112319.htm. Acesso em: 13/08/2018.

BRASIL. Declaração de Salamanca e linha de ação sobre necessidades educativas especiais. 2. ed. Brasília, DF: Corde, 1997.

BRASIL. Plano Nacional de Educação. Ministério da Educação/Secretaria de Articulação com os Sistemas de Ensino (MEC/Sase): Brasília, DF. 2014. 
FAVORITO, W.; SILVA, I. Os surdos na escola: letramento e bilinguismo. Campinas: UNICAMP/MEC, 2008.

GESSER, Audrei. LIBRAS? que língua é essa?: Crenças e preconceitos em torno da língua de sinais e da realidade surda. São Paulo: Parábola, 2009.

KYLE e WOLL. Languege in sign: an interpretational perspective on sign language. London: Croom Helm: 1985.

ONU. Convenção sobre os Direitos das Pessoas com Deficiência. Brasília, DF, 2006. Disponível em: http://www.planalto.gov.br/ccivil_03/_ato20072010/2009/decreto/d6949.htm. Acesso em: 13/08/2018.

QUADROS, R.M. Educação de Surdos: a aquisição da linguagem. São Paulo: Artmed, 2009.

REILY, L. H. Educação Inclusiva: linguagem e mediação. São Paulo: Papirus, 2004.

SCHLATTER, M.; GARCEZ, P. M. Educação linguística e aprendizagem de uma língua adicional na escola. In: Referencias curriculares do Estado do Rio Grande do Sul: linguagens, códigos e suas tecnologias. Porto Alegre: Secretaria de Estado da Educação/Departamento Pedagógico, 2009.

SCHLATTER, M.; GARCEZ, P. M. (2012). Línguas adicionais na escola: aprendizagens colaborativas em inglês. Erechim, RS: Edelbra, 2012.

SILVA, S.; VIZIM, M. (Org.). Educação especial: múltiplas leituras e significados. Campinas: Mercado das Letras; Associação de Leitura do Brasil, 2001.

STOKOE, W. Sign and Culture: A Reader for Students of American Sign Language. Listok Press, Silver Spring, MD, 1960.

SKLIAR, C. A Surdez: um olhar sobre as diferenças. 1 ed. Porto Alegre: Mediação, 1999. 